\title{
Perception of Secondary School Teachers on Sources of Stress and Coping Strategies: A Case of Ludewa District, Tanzania
}

\author{
Amina Thomas \\ University of Iringa, Tanzania \\ Corresponding Mail: hauleamina@gmail.com
}

\begin{abstract}
The study aimed at identifying perceived sources of stress and coping strategies among secondary school teachers in Ludewa District. The study was guided by Transactional or Cognitive Theory of Psychological Stress and Coping. It employed the quantitative approach through descriptive statistics in terms of frequencies and percentages. Through simple random sampling, eight out of 22 schools were selected to participate in the study. From the eight schools, 100 teachers were selected through simple random sampling but the response rate was 74 . Therefore, 74 teachers participated to fill the questionnaire. The first category of perceived stressors is for those which were very highly rated: delay in promotion, poor working condition, low salary for work, worried from student performance, overwork and lack of time to spend with family. The second category is for those which were highly rated: poor administrations, lack of social services, loans from different organizations, benefit from work and students' misbehavior. Lowly rated source of stress was attending duties on weekends while very lowly rated sources were little acknowledgment from superior and trouble with colleagues. The study gives a number of recommendations; these include that the government should employ more teachers to reduce teachers' overwork which is cited as one of stressors. Heads of schools should involve all teachers in decision making and treat them equally. School under investigation should employ mentoring and counseling techniques which will motivate teachers to share their economic and social problems in order to curb unnecessary stresses. Finally, teachers should employ such stress management strategies as joining in social clubs, attending physical exercises like sports and games and seeking support from either co- workers or supervisors in order to curb stressful challenges.
\end{abstract}

Keywords: Work related stress, teachers' stress, coping strategies, stressors

\section{Introduction}

Stress is defined as a situation which exceeds an individual's coping abilities and therefore poses a threat to an individual's mental and physical health (Bullo and Sanchez (2014. Worldwide, stress has been recognized as a concern among professionals employed in human service occupations and is of increasing concern for those in the teaching profession. According to the World Health Organization (2017), stress is categorized as "the health epidemic of the 21st century" which brings harm to people, including teachers. Moreover, the World Health Organization (WHO) (2017) claims that over $50 \%$ of people who visit physicians in the world may be affected by problems and disorders related to either internal or external work related stressors. WHO (2017), presented that more than
300 million people were affected by work related stress globally. The study by Eres and Atanasoska (2011) in Turkey and Sweden presented the report that teachers' health may be affected negatively due to stress. In Africa, it has been found that workrelated stress is experienced by teachers at their work place, particularly in countries like Nigeria, Botswana, South Africa, Swaziland, Tanzania and Kenya just like elsewhere in the world (Okeke \& Dlamini, 2013).

According to Mkumbo (2013), schools are the central stressor which may affect prosperity of education system in Tanzania. The stressor results from various factors including lack of collaborative school culture where teachers are not involved in decision making processes. 
While stressful experience hinders teachers from effective performance of daily duties, a study by Richards (2012) advised that work-related stress should be managed through social support from friends, co-workers and family members. Babatunde (2013) adds that education systems need to regularly ensure availability of supportive environment to address stressful experiences of teachers.

Ludewa district is found in the outskirts of Tanzania and in rural areas where teachers face a number of challenges. For example, the area has poor communication network, transport problem, absence of clean water, lack of electricity supply and poor health services (URT, 2018-2022). While these challenges are likely to bring stressful conditions to teachers, this study sought to establish sources of work related stress and coping strategies by secondary school teachers in Ludewa District. The study was guided by the following research questions:

1. What are perceived sources of stress by secondary school teachers in Ludewa District?

2. What are possible coping strategies as perceived by teachers to curb stress by secondary school teachers in Ludewa District?

\section{Literature Review}

This section presents literature review which involves the theoretical underpinnings and factors responsible for stress on secondary school teachers.

\section{Theoretical underpinnings}

This study was guided by the transactional theory of stress and coping which was established by Lazarus and Folkman (1986, 1987). Transactional theory suggests that stress is the direct product of a transaction between an individual and the environment which may tax resources and thus threaten the wellbeing. For instance when teachers have more workload to do, poor students 'discipline, low salaries and a working environment which is not friendly, the work becomes more stressful. This theory explains that when teachers appraise their working as a challenge, stress can bring them a sense of competence and an increased capacity to teach. When work is seen as a threat, however, stress can elicit feelings of helplessness and develop a sense of loss, hence poor performance.

If a situation is evaluated as potentially stressful, then secondary appraisal occurs and the individual evaluates if the potential harm can be altered, avoided or prevented (Park \&Folkman, 1997), where to assign blame or credit, and what future expectations are. Lazarus and Folkman (1984) point out that people and groups of people differ in sensitivity and vulnerability to certain types of stressors, as well as in the interpretation responding to those stressors. Based on this theory, cognitive evaluation is the process of judgment which determines the level of adjustment methods available for each person. It includes identifying available resources and options, which will help the person to negotiate with potential or actual demands. Lazarus and Folkman (1980) described many types of coping behaviors and suggested that they could be aggregated into two major categories of coping response: problem-focused coping or emotion-focused coping. The authors further argued that, the effectiveness of coping strategies that an individual may use depends on various factors such as the number, duration and intensity of stress sources, previous experiences of the individual, available support systems and the personal abilities. In this context, this model is relevant and may be applicable to assess sources of stress and coping strategies. The effectiveness of coping strategies that an individual may use depends on various factors such as the number, duration and intensity of stress sources, previous experiences of the individual, available support systems and the personal abilities. In relation to this context this model is relevant, suitable and may be applied to assess sources, as well as coping strategies of stress for secondary school teachers. It considers cognitive approaches, and it is a dynamic model in the fact that it is for the individuals to change their appraisal and cope with stress which varies very much and finally identifies the methods for managing psychological responses to stressors (Lazarus, 1999). Finally, this theory helps teachers to be able to identify the changes which may predict their health.

\section{Sources of work-related Stress}

Based on Transactional theory, when teachers evaluate work environments as a stress, the experience can elicit feelings of helplessness and develop a sense of loss, hence poor performances. For instance, when teachers have more workload to do, poor students 'discipline, low salaries and a working environment which is not friendly for them, the work becomes more stressful. This theory is similar to the studies like that of A study by Kirigo

\section{East African Journal of Education and Social Sciences (EAJESS) 2(4)46-53}


and James (2016) on the influence of occupational stress on teachers' performance in public secondary schools in Kenya established that teachers have many activities to carry out in the process of executing their main duty of teaching. These include preparing professional documents including lesson plan, schemes of work, records of work and student progress record as well as administering, marking and analyzing examinations in carrying out other duties other than teaching.

Okeke and Dlamini (2013) investigated stressors that impinge on teachers in secondary schools in Swaziland and suggest that excessive workload is found to be a major cause of teacher stress in Swaziland. These create lots of sufferings and stress which may affect teachers' health and school performances because stressed teachers cannot be able to fulfill teaching responsibility appropriately through this study the government would see the need of employing more teachers so as to solve the issue of overwork load.

Kaupa (2020) in the study of the sources and impact of stress of teachers on the performance of learners in Namibia revealed that work stress does exist in high school teachers due to the stressful nature of their work and noted that the key drivers of work stress amongst high school teachers is poor working conditions. Also, Nelly (2016) asserted that the source of stress in Sumbawanga Municipality is poor working conditions, overwork load and low salary.

Okeke, Adu, Drake and Duku (2014) conducted a study on the causes of stress among Pre-school educators in South Africa and found that indiscipline of students leads to rise of stress levels among teachers. Amanda (2016) conducted a qualitative study on sources of stress perceptions of South African teachers and found that stress of teachers resulted from student misbehaviors.

Manabete, Makinde and Duwa (2016) studied job stress among school administrators and teachers in Nigerian secondary schools and technical colleges and revealed that poor relations with supervisors, was a source of stress among teachers. Mkumbo (2013) argued that school is the central stressor in Tanzania. He asserted that if a school lacks collaborative culture, it may lead to poor recognition of teachers because only the chosen few who will be in power will have the right to decide all school matters. This makes those teachers who are not involved in school decisions to feel stressed since they feel they are not part of teacher's staff and they have nothing to contribute to the development of school.

Ekundayo and Kolawole (2013) found that secondary school teachers were stressed by several conditions such as an unsupportive working environment, lack of proper communication channels between supervisors and their subordinates as well as low payment of wages and salaries. They portrayed clearly on the sources of stress with little managing strategies which will be used as the gap to be filled by this study.

Mlaki (2011) studied on determinants of stress among primary school head teachers and found that occupational stressors among head teachers in Primary schools were poor promotion and payment system, shortage of teaching and learning resources, teaching overcrowded classes, shortage of teachers, frequent curriculum changes, transport problems, problem of poor living conditions as well as handling difficult parents/ guardians and community. The system of payment and promotion of primary teachers and secondary teachers as well as living conditions in Tanzania are almost the same based on the theory that different people sense differently so this study secondary school teachers evaluate these.

\section{Coping Strategies of Stress}

Based on transaction theory, people can use different coping strategies by judging which adjustment methods available that each person would use to manage stress. This study will enable teachers and education stakeholders to use effective stress coping strategies to relieve stress they have in life so as to live happier, healthier and more productive. While some teachers may opt to use alcohol so as to forget the pain of stress, others may talk to friends and colleagues so as to share experience and by talking, they release the stress. Margaret, Ngigi and Mutisya (2018) investigated on stress and coping strategies among Teachers in Kenya and advised that counseling services, physical exercises, religious intervention are among coping strategies teachers can use to reduce level of stress. Religious intervention may fill people with hope and optimism rather than despair; it may also offer the physiological benefits of relaxation in prayer, provide a community life line of social support to prevent isolation and promote a safe and healthy ways of living.

The study of Gerard, Wendi and Mike (2016) on stress and coping among secondary school teachers 
in Australia revealed that the most common coping strategies reported were talking to friends and family members as well as physical exercises. The talking strategy helps teachers to express their feelings to their families and friends and by doing so stress is reduced. Physical exercise, on the other hand, changes the thinking from negative to positive way; hence one feels better about one-self. Reddy and Anuradha (2013) conducted a study in India on occupational stress of teachers working at higher secondary level and suggested measures which could provide benefit to teachers in coping with stress. The measures include practicing yoga and meditation, exercising regularly andhaving a supportive friend circle. This helps to improve selfesteem, build self-confidence, develop a good sense of humour and live a happier life. This also increases ability to manage difficulty stressful situation. Ekundayo and Kolawole (2013), in their study on stress among secondary school teachers in Ekiti State, Nigeria, revealed that manageable time is the strategy for coping with stress.

Furthermore a study conducted by Sadick (2019) in Tanzania recommended seeking support from others, professional counseling and physical exercise as main techniques in coping with stress. Social support can be done through teamwork that results in teachers sharing knowledge and experience about different issues

\section{Research Methodology}

This study employed the cross- sectional survey design was used to guide this study. Through simple random sampling, eight out of 22 schools were selected to participate in the study. From the eight schools, 100 were selected through simple random sampling but the response rate was 74 . Therefore, 74 teachers participated to fill the questionnaire.

\section{Data Collection Method}

Primary data was collected through questionnaires and Secondary data was captured through documentary review. Closed-ended questionnaire was used in order to enable the researcher to reach respondents' easier.

\section{Statistical Treatment of Data}

The coding sheet was prepared for entering data followed by data cleaning. Frequencies and percentages were the output of the Descriptive Statistical analysis. Data was presented in tabular forms through the SPSS to be able to show how one category varies from another category. The method was used because it can save space and it simplifies the comparison of variables.

\section{Validity and Reliability}

The Questionnaires was checked by the research supervisor from University of Iringa to strengthen the validity. To establish consistency of the questionnaire results, the teachers, head of schools and district secondary education officer's questionnaire was pretested and the Cronbach Alpha method was used to establish reliability of the questionnaires. The test yielded the Cronbach Alpha of 0.845. According to Marczy, Matteo and Festinger (2005), this was a high level of internal consistency and therefore the questionnaire was reliable.

\section{Ethical Considerations}

Since the research involved people, respondents were contacted and invited to participate in the study on a voluntary basis. Before involvement, participants were asked for an informed consent and their views were respected also the issues confidentiality were considered.

\section{Results and Discussion}

The study sought to establish sources of workrelated stress and coping strategies among secondary school teachers in Ludewa District. Data were presented by using tables in terms of frequencies and percentages. Of the 74 teachers who filled the questionnaire, 54 were males while 20 were females. Thirteen were single while 58 were married, one was divorced and two were widows. Twenty-one had the experience of 0 to 5 years while 35 had the experience of 6 to 10 years and 10 had the experience of more than ten years. Therefore, a variety of demographics were considered in the construction of the sample.

Research question 1: What are perceived sources of stress by secondary school teachers in Ludewa District?

This section provides sources of stress by secondary school teachers in Ludewa District. Information for this research question was obtained through questionnaire which was administered to teachers as reflected in Table 1.

Tables 1 lists potential sources of stress whereby respondents were asked to indicate their agreement or disagreement with the items in the table. Possible sources of stress were categorized into four groups: very highly rated sources with the score of $75 \%$ to $100 \%$, highly rated sources with the score of

\section{East African Journal of Education and Social Sciences (EAJESS) 2(4)46-53}


$50 \%$ to $74 \%$, lowly rated sources with the score of $25 \%$ to $49 \%$ and very lowly rated or insignificant sources with the score of below $25 \%$.

Very highly rated sources of stress were six out of 14 possible sources: These include delay in promotion (95.3\%), poor working Condition (93.8\%), low salary for work (92.3\%), worried from student performance (90.8\%), Overwork load (76.9\%) and lack of time to spent with family (75.4\%). Some of the very highly rated sources of stress are supported by previous studies such as of Ekundayo and Kolawole (2013) in Nigeria and Mlaki (2012) in
Tanzania. The findings of all these studies revealed that poor working was a major source of stress which caused them not to be comfortable with the environment which also can cause their working effectiveness to be lowered. On the other hand, the findings are supported by studies of Kirigo and James (2016) in Kenya as well as of Sadick (2019) in Tanzania which found that overwork load is the main source of stress whereby teachers were found to have many activities to carry out in the process of executing their main duty of teaching.

Table 1: Perceived Sources of Stress by Secondary School Teachers

\begin{tabular}{|c|c|c|c|c|c|c|c|}
\hline \multirow[t]{2}{*}{ SN } & \multirow[t]{2}{*}{ Potential Source of Stress } & \multicolumn{2}{|c|}{ Agree } & \multicolumn{2}{|c|}{ Neutral } & \multicolumn{2}{|c|}{ Disagree } \\
\hline & & f & $\%$ & f & $\%$ & f & $\%$ \\
\hline 1 & Delay in Promotions & 62 & 95.3 & 0 & 0 & 3 & 4.6 \\
\hline 2 & Poor working Condition & 61 & 93.8 & 0 & 0 & 5 & 7.7 \\
\hline 3 & low salary for work & 60 & 92.3 & 0 & 0 & 5 & 7.7 \\
\hline 4 & Worried from student performance & 59 & 90.8 & 3 & 4.6 & 3 & 4.6 \\
\hline 5 & Overwork load & 50 & 76.9 & 5 & 7.7 & 10 & 15.4 \\
\hline 6 & Lack of time to spent with family & 49 & 75.4 & 10 & 15.4 & 6 & 9.2 \\
\hline 7 & Poor administration & 40 & 61,5 & 8 & 12.3 & 17 & 26.2 \\
\hline 8 & Lack of Social Services & 41 & 60.1 & 4 & 6.2 & 20 & 30.1 \\
\hline 9 & Loans from different Organizations & 36 & 55.4 & 14 & 21.5 & 15 & 23.1 \\
\hline 10 & Benefit from work & 36 & 55.4 & 9 & 13.8 & 20 & 30.1 \\
\hline 11 & Misbehavior of student's & 36 & 55.4 & 7 & 10.8 & 22 & 33.8 \\
\hline 12 & Attending duties on weekends & 28 & 43.1 & 11 & 16.9 & 26 & 40 \\
\hline 13 & Little acknowledgement From supervisor & 15 & 23.1 & 24 & 36.9 & 26 & 40 \\
\hline 14 & Trouble with colleague & 8 & 12.5 & 25 & 38.5 & 32 & 49.2 \\
\hline
\end{tabular}

Highly rated sources of stress were five out of 14 possible sources: These included poor administrations $(61.5 \%)$, lack of social services (60.1\%), loans from different organizations (55.4\%), benefit from work (55.4\%) and students' misbehavior (55.4). Similarly, study findings of Mkumbo (2013) in Tanzania and Manabete, Makinde and Duwa (2016) in Nigerian established that poor administration is among the main sources of stress for teachers in secondary schools. Poor administration may lead to lack of collaborative culture which results in poor recognition of some of the teachers because only a few chosen are recognized.

Lowly rated source of stress was one out of 14 possible sources: This was attending duties on weekends (43.1\%). On the other hand, very lowly rated source of stress were two out of 14 possible sources: These were little acknowledgment from superior and trouble with colleagues (12.5\%).
Research question 2: What are possible coping strategies as perceived by teachers to curb stress by secondary school teachers in Ludewa District?

This research question provides findings on the perceived coping strategies that can help to manage the level of stress by secondary school teachers. As seen in table 2 , very highly rated coping strategies were four out of 14 possible sources: These include social support and help from others (83.1\%), talking with others $(81.5 \%)$, engaging in physical activities (78.5\%) and recreational and leisure activities (78.5\%). Previous studies of John and Natsirayi (2012) in Zimbabwe, Nelly (2016) in Tanzania and Uchendu and Ukonu (2016) in Nigeria found that secondary school teachers cope with stress by Social-support networks, particularly interactions with family and friends.

Highly rated coping strategies were five out of 14 possible sources: These included Physical exercises and sports (73.8\%), knowledge and techniques to deal with stress $(68.8 \%)$, watching movies $(66.1 \%$, reading magazines and stories (64.6\%) and prayers 
or meditation (62.2\%). On the other hand, lowly rated measure was one, walking around $(44.6 \%$ while very lowly rated measures were two out of twelve:

Table 2: Proposed Stress Coping Strategies

\begin{tabular}{llllllll}
\hline SN & Coping Strategies & \multicolumn{2}{c}{ AGREE } & \multicolumn{3}{c}{ NEUTRAL } & \multicolumn{2}{c}{ DISAGREE } \\
& & $\mathbf{f}$ & $\mathbf{\%}$ & $\mathbf{f}$ & $\mathbf{\%}$ & $\mathbf{f}$ & \% \\
\hline 1 & Social support and help from others & 54 & 83,1 & 8 & 12.3 & 3 & 4.6 \\
2 & Talking with others & 53 & 81.5 & 6 & 9.2 & 6 & 9.2 \\
3 & Engaging in physical activities & 51 & 78.5 & 10 & 15.4 & 4 & 6.2 \\
4 & Recreational and Leisure activities & 51 & 78.5 & 10 & 15.4 & 4 & 6.2 \\
5 & Physical Exercise and Spots & 48 & 73.8 & 8 & 12.3 & 9 & 13.8 \\
6 & Knowledge and techniques to deal with Stress & 44 & 68.8 & 11 & 16.9 & 9 & 13.8 \\
7 & Watching Movies & 43 & 66.1 & 10 & 15.4 & 11 & 16.9 \\
8 & Reading magazines and stories. & 42 & 64.6 & 12 & 18.5 & 16 & 24.6 \\
9 & Prayers or meditation & 45 & 62.2 & 9 & 13.8 & 8 & 12.3 \\
10 & Walking around & 29 & 44.6 & 16 & 24.6 & 10 & 15.4 \\
11 & Using prescribed drug & 8 & 12.3 & 9 & 13.8 & 48 & 73.8 \\
12 & Consumption of alcohol, Drugs abuse and smoking & 7 & 10.8 & 4 & 6.4 & 54 & 83.1 \\
\hline
\end{tabular}

using prescribed drugs (12.3\%) and Consumption of alcohol, Drug abuse and smoking (10.8\%). Consumption of alcohol and smoking was rated the least and this could be because teachers are role models and therefore cannot advocate for the use of illegal drugs aw ways of alleviating stressful experiences.

\section{Conclusions and Recommendations}

The study concludes that all 14 listed items were considered by teachers as possible sources of stress under different ratings. Particularly, there are four categories of perceived sources of stress. The first category is for those which were very highly rated: delay in promotion, poor working condition, low salary for work, worried from student performance, overwork and lack of time to spend with family. The second category is for those which were highly rated: poor administrations, lack of social services, loans from different organizations, benefit from work and students' misbehavior. Lowly rated source of stress was attending duties on weekends while very lowly rated sources were little acknowledgment from superior and trouble with colleagues.

Based on conclusions of the study, the following recommendations are given: The Government should employ more teachers to reduce teachers' overwork which is cited as one of stressors. This will help secondary school teachers to balance their responsibilities and handle them more effectively while reducing possibilities to get stressed. Heads of schools should involve all teachers in decision making and treat all teachers equally. This will help teachers to feel they are important in their schools and as a result, they will work happier. School under investigation should employ mentoring and counseling techniques which will motivate teachers to share their economic and social problems in order to curb unnecessary stresses. The schools should improve working environments by providing communication facilities like computers, internet and telephones to make the work of the teachers easier. Finally, teachers are advised to employ such stress management strategies as joining in social clubs, attending physical exercises like sports and games and seeking support from either co- workers or supervisors in order to curb stressful challenges.

\section{References}

Amanda, B. (2016). Sources of Stress: Perceptions of South African TESOL Teachers 1205-1213, 2016 DOI: 10.13189/ujer.2016.040534.

Babatunde, A. (2013). Occupational Stress: A Review on Conceptualizations, Causes and Cure', Trends \& Challenges, 65 (3), 73.

Bullo, J. G., \& Sanchez, M. G. (2014). Sources of stress among college students. CVCITC Research Journal, 1(1), 1 6-25.

Ekundayo, H. \& Kolawole, A. (2013). Stress among Secondary School Teachers in Ekiti State, Nigeria. Journal of Educational and Social Research, 3(2), 311- 315.

Eres F. and Atanasoska T., (2011). Occupational stress of teachers: A comparative study Between Turkey and Macedonia. International Journal of Humanities and Social Science. 7(1), 59-65. 
Gerard. F.,Wendi. B. \& Mike (2016) secondary school teacher stress and coping: insights from Queensland, Australia International Journal of Arts \& Sciences, and CD-ROM. ISSN: 1944-6934: 09(02):597-608.

John. S. M., \& Natsirayi C. (2012) Teaching Practice generated stressors and coping mechanisms among student teachers in Zimbabwe EASA (32)1, 55-166.

Kaupa, S. (2020). The Sources and Impact of Stress of Teachers on the Performance of Learners: Journal of International Business Research and Marketing, in Namibia DOI: 10.18775/jibrm.18498558.2015.54.3002.

Kirigo, G. and James, M. (2016). Influence of Occupational Stress on Teachers' Performance in Public Secondary Schools in Nyeri County, Nyeri South Sub County Kenya Millicent International Journal of Business and Management Invention.

Lazarus, R. S. (1999). Stress and Emotion: A new synthesis. NY: Springer Publishing Company.

Lazarus, R. S. \& Folkman, S. (1986, 1987). Transactional Theory and Research on Emotions and Coping'. European Journal of Personality 1 (3), 141-169.

Lazarus, R. S. \& Folkman, S. (1984). Stress, Appraisal, and Coping. New York: Springer.

Lazarus, R. S. \& Folkman, S. (1980). An analysis of coping in a middle-aged community sample. Journal of Health and Social Behavior, 21, pp. 219-239.

Marczyk, G. DeMatteo, D. Festinger, D. (2005). Essentials of Research Design and Methodology. John Wiley \& Sons, Inc., Hoboken, New Jersey.

Manabete, D.S.S., John, C.A., Makinde, A. A., \& Duwa, S.T. (2016). Job Stress among School Teachers in Nigerian Secondary Schools and Technical Colleges. International Journal of Education, Learning and Development, 4(2), 9-24.

Margaret, K. Ngigi, S. \& Mutisya, S. (2018) Stress and Coping Strategies among Teachers in
Institutions in Kenya.Work and Stress, 15(4), 328-346.

Mkumbo, K. (2013). Prevalence of and Factors Associated with Work Stress in Academia in Tanzania. International Journal of Higher Education, 3(1), 1-11.

Mlaki, E. (2011). Determinants of Occupational Stress among Primary School Head Teachers in Dodoma Urban and Chamwino District Tanzania: Unpublished Doctoral Thesis. Dodoma: The University of Dodoma.

Mlaki, E. (2012). Contribution of school location in manifestations of stress among public primary School head teachers in Tanzania Unpublished Doctoral Thesis. Dodoma: The University of Dodoma.

Nelly, K. (2016). Effects of stress on secondary school teachers' job performance in Tanzania: case study of Sumbawanga Municipality.The University of Dododoma. http://hdl. handle.net/20.500.12661/1301.

Okeke C. I. O, \& Dlamini, S. C. (2013). An empirical study of stressors that impinge on Teachers in Secondary School in Swaziland. South African Journal of Education, 33(1): 32.

Okeke C. I. O, Adu E. O, Drake M. L., \& Duku, N. S. (2014). Correlating demographic Variables with occupational stress and coping strategies of pre-school educators: A literature review. Journal of Psychology, 5(2): 143-154.

Park, C. L. \& Folkman, S. (1997), Meaning in the context of stress and coping, Review of General Psychology, 2, 115-144.

Reddy, R. \& Anuradha, P. (2013). A study on the school physical environment. Industrial Pollution Control, 22(1), 73-76.

Richards, J. (2012). Teacher Stress and Coping Strategies: A National Snapshot. The educational forum 76(3), 299-316.

Sadick J, C. (2019). The implications of work-related stress among Secondary School Teachers in Tanzania: The Case of Tanganyika District in Katavi.The University Dodoma, Dodoma.http://hdl.handle.net/20.500.1266 $1 / 1924$. 
Uchendu, U. I., \& Ukonu, O. I. (2016). Effect of Substance Use on Academic Performance among Secondary school teachers of Abuja, Nigeria Journal of Research in Humanities and Social 7:185-200.

United Republic Of Tanzania URT. (2018 - 2022). President's Office Regional Administration and Local Government Njombe Regional
Education Strategic Plan. http://w ww.n jombe.go.tz/storage/app/media/uploadedfiles/Njombe\%20Region\%2Education\%20 Strategic\%20Plan.pdf.

World Health Organization WHO. (2017). Mental Health Action Plan 2013-2020, World Health Organization. 